\title{
THE PROBLEM OF EARLY DIAGNOSIS IN PULMONARY TUBERCULOSIS
}

\author{
C. H. C. TOUSSAINT, M.R.C.S., L.R.C.P., D.P.H. \\ (Deputy M.O.H. and Clinical Tub. Off. Borough of Bermondsey), \\ and E. K. PRITCHARD, M.R.C.S., L.R.C.P., D.P.H. \\ (Deputy M.O.H. and Clinical Tub. Off. Borough of Southwark)
}

It should be regarded as a sound axiom that the administrative scheme for the control of any disease must be based on the clinical conceptions of the disorder. The late Metropolitan Asylums Board built up a classical and excellent example of such a precept in their administration of the admission and treatment of the acute infectious diseases within the Metropolis. Within an hour or less, of the diagnosis being made by the practitioner, the patient was usually in hospital and under expert treatment. No paper forms were required, admission was secured by a telephone message from the practitioner, who had but to leave a certificate at the patient's house. The objects of such a scheme were two-fold. Firstly, admission had to be prompt, so as to place the sufferer under skilled attention with a view to preventing a fatal issue (e.g. Diphtheria-though the same scheme was applied equally to other infections). Secondly, by immediate isolation of the patient in a fever hospital it was possible to prevent the spread of infection to others in the household, or even, in some cases (e.g. Smallpox) to the community at large.

In contrast to such a scheme let us consider the administration of tuberculosis-with particular reference to the pulmonary form of the disease. Pulmonary tuberculosis, also, is an infectious disease, and on this account the notification of any new case to the local Medical Officer of Health became compulsory in I9I2. The institution of notification, however, was not accompanied by comprehensive schemes for the immediate treatment of the tuberculous patient, and, largely owing to the war, it was not until I92I that local authorities throughout the country were required to establish and administer schemes for the diagnosis, treatment, and after-care of sufferers from this disease. Since that time, thousands and thousands of pounds have been spent on the administration of tuberculosis. Much of this has gone on routine treatment of rest and graduated exercise, along conservative lines, while in other areas great sums have been spent on the erection of elaborate buildings, with every facility for the most up-to-date thoracic surgery.

What of the achievements gained? We have, it is true, witnessed a tremendous fall in tuberculosis mortality since the middle of last century. We must beware, however, lest we ascribe this fall, solely, or even in large part, to the excellence of our administration. We would recall the Medical Research Committee's comment in the introduction to Brownlee's report (1) on "An Investigation into the Epidemiology of Phthisis in Great Britain and Ireland":-

"These changes-happily for the most recent generations-are in the direction of decline. They must be regarded as 'inherent,' as due, that is to say, to the intrinsic biological properties of the disease, for it is plain not only that they should not without evidence be attributed to national hygienic improvement, but that in large part they certainly cannot upon the evidence be so accounted for. The decline is most naturally to be regarded as the ebb of a long epidemic wave to be succeeded perhaps, indeed probably, by the rise of the next wave in its turn-unless science can find the way of interference-and its explanation can only be given by further study."

Little credit is due, then, to past or present administrations for the fall in mortality-which indeed started over half a century before the introduction of our schemes-and if we are to win commendation for positive achievements there are certain aspects of the situation which must be faced, and which we must learn to circumvent.

A perusal of annual reports issued by Medical Officers of Health (1938) reveals the following:

It is the rule, rather than the exception, in the industrial districts of England and Wales, and in the county areas adjoining the metropolis, for approximately 50 per cent of all deaths from pulmonary tuberculosis to occur within the period of one year following the notification of such cases. (In other words, throughout the country only a short period elapses between notification and death in a very large number of cases, amounting in many districts to half the total number.)

A recent paper by Brian Thompson, (11) in which he relates the fate of 406 patients with cavi- 
tory pulmonary tuberculosis, fully reveals this grave situation from another angle. We cannot do better than quote two passages from his summary:-

"The early case fatality was particularly striking, 42 per cent of the patients dying within twelve months of diagnosis. At the end of the first five years, three-quarters of the original total were dead, and of the survivors one-half died within the second five years. In other words of any eight patients with positive sputum, only two would be expected to survive five years and one to survive ten years.

There are indications that these high fatality rates are not exceptional for an industrial community of the type under consideration. and therefore the discovery of tubercle bacilli in the sputum is, individual considerations apart, of grave prognostic significance."

Consistent with this serious outlook in sputum positive cases we find also that far too many patients enter sanatoria in advanced stages of the disease, beds become hopelessly blocked, and huge sums of money are spent on the temporary restoration of chronic invalids and on rehabilitation, but without attaining the real aim of final cure.

One or other only of two reasons can be adduced to account for this very unsatisfactory position. Either pulmonary tuberculosis has a long insidious period of apparent quiescence before it can be detected, or it is a disease which, more often than is realised, assumes also an acute form with a moderately sudden onset and a rapid spread.

Constant study of advanced cases in the tuberculosis wards of general hospitals has caused us to ponder on this problem and has led us to the conclusion that the vast bulk of patients who come under treatment in a moderately advanced state-with a short expectation of life-are those in whom the onset of disease was comparatively sudden-in a previously healthy person-and the subsequent spread more often rapid than slow.

The sudden onset of pulmonary tuberculosis and its subsequent rapid spread throughout the lung substance is by no means a new theory. It is not stressed-if mentioned at all-in any. standard textbook of medicine, and this no doubt accounts for ignorance on the part of general practitioners to whom such ideas were never revealed in their student days.

Doubt as to the veracity of original views on the universal chronicity and slow evolution of pulmonary tuberculosis in the adult were cast from two sources-one epidemiological, and the other clinical.

In recent years investigations in Scandinavia and in America have suggested that the non-reacting (or Mantoux negative) adolescent stands in greater danger when exposed to a fairly severe tuberculous infection than does the previously Mantoux positive, or allergic individual who appears, as a result of his triumph over a past infection, to have acquired some degree of immunity. If this theory be true, and it is at present under full investigation in this country, it provides testimony, in agreement with the clinical evidence to be mentioned shortly, of the frequent onset of rapid and spreading disease in a previously healthy person (not uncommonly in an athlete of good physique). In the early part of the century it used to be thought that, by the age of adolescence, the vast bulk of the population had already met with tuberculous infection, and thus reacted to tuberculin. Recent surveys have shown, however, that some 40 per cent-more or less-of adolescents may be going out into the world of office, factory and workshop without any previous encounter with tuberculous infection. It is, indeed, reasonable to assume that, as the tuberculosis mortality (and infection) has fallen throughout the years since 1850 , so has the proportion of adolescents susceptible to infection been growing. It is almost certainly in this group that there arise many of the acute lesions-fatal within a few months to a year of onset, in the absence of rapid diagnosis and treatment-and preceded, even shortly before the onset of the disease, by radiograms showing lungs quite clear of abnormal shadows (vide plate).

We have attempted, further, to illustrate this epidemiological theory in Charts I and 2. The death rates per million living at each group of the population are usually charted in the form of a mortality curve. Such curves of tuberculosis mortality are liable to show peaks at three age groups, i.e. infancy, adolescence and middle age. (In some areas a further peak, due to senile mortality, may be shown.) Following on the abnormal incidence of mortality in different age groups (illustrated by these peaks) Brownlee conceived the possibility that "Phthisis pulmonalis is not a single disease, as is commonly understood, but rather a group of diseases, coming thus into line with typhoid fever and bacillary dysentery, both of which are now known to consist of groups of diseases of which the causal organisms possess similar properties and produce fevers which run almost the same course." 
In Chart I we have attempted to analyse a typical tuberculosis mortality curve (e.g. the curve of I92I-I929, Chart 2) with a view to showing the reactions of three differing groups of the population to the same bacillus, i.e. it is, we believe, the same disease which is responsible for the three peaks of infancy, adolescence, and middle age (though the clinical type of disease in each group may be of a different character).

Evidence of the risk to children in tuberculous households has been described by Lissant Cox (3); Dow and Lloyd (4); and Toussaint and MacIntyre. (12)

The passage of infection from the chronic middle aged tuberculous worker to the adolescent is not an easy matter to illustrate, though an excellent example has been reported by Tattersall.(10) (The occurrence of two consecutive cases of acute disease in adolescent typists was shown to be due to infection from a previously unsuspected elderly clerk, a chronic bronchitic (sic), whose sputum was found to be positive.)

The middle-aged sufferer must at some time have passed through group A or group B (Chart I), and in the case mentioned it is possible that the strain of industry, or of an unfavourable environment, does lead to the breakdown of a pre-existing immunity, as contrasted with the infant and the adolescent where the vital factor is the exposure to massive infection of a susceptible suspect.

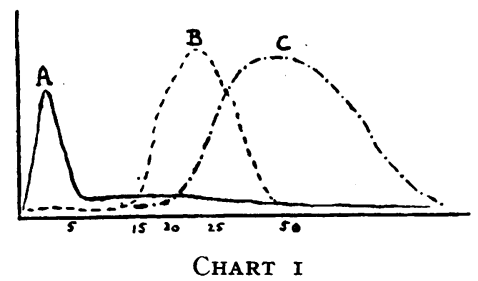

Group A.-Children born into tuberculous households.-Children of Group C. A proportion succumb to tuberculosis. The survivors become immune (react to tuberculin) and have little or no share in the rise shown by Group B.

Group B.-Children born into households free from tuberculosis. They do not react to tuberculin during childhood and are susceptible on meeting with tuberculous infection in office and workshop after leaving school. (Mortality between the ages of 5 to $I 5$ is low because those still alive in Group A have acquired immunity, and those who will later constitute Groups $B$ and $C$ have not yet met with the massive infection which will disable them.)

Group C.-Fathers and mothers (infectors) of Group A. Also infectors of Group B. (Infection may also occur from one to another of Group B, and from Group B to Group A.)

In Chart 2 we have endeavoured to portray the factors concerned in the epidemiology of pulmonary tuberculosis, based on the assumptions mentioned above.

It must not be presumed that we consider allergy and immunity to be identical, for the true nature of each remains, for the present, hidden in obscurity. There can be no doubt, however, that the individual who overcomes a previous infection, and develops a subsequent immunity to tuberculosis, also becomes allergic (reacts positively to tuberculin), and that this reaction, except in rare instances, tends to remain permanent.

We have, in preceding paragraphs, elaborated a theory propounded by Coutts. (2) This was subjected to criticism by Bradford Hill,(6) after which it faded into the background. Nor was it regarded favourably by Hart and Wright. (5) Coutts, however, maintained faith in his theory, considering that it held the field, until some further evidence is available, as one of the main factors in the problem. With him we would agree, and suggest that later findings tend to support rather than destroy his supposition.

A true appreciation of the clinical factors involved in the onset of pulmonary tuberculosis in the adult came first from Continental physicians, of whom Rist (of Paris) was an outstanding advocate. Since the days of Laennec, the French school of pathologists had repeatedly and persistently insisted upon the fact that, alongside with true tubercle, one always found in the lungs of consumptive people patches of pneumonic lesions of the inflammatory type, which belonged just as truly to tuberculous disease as tubercle itself. (8) The advent of radiology con- 


\section{THE SUDDEN APPEARANCE OF ACUTE LESIONS IN THE YOUNG ADULT}

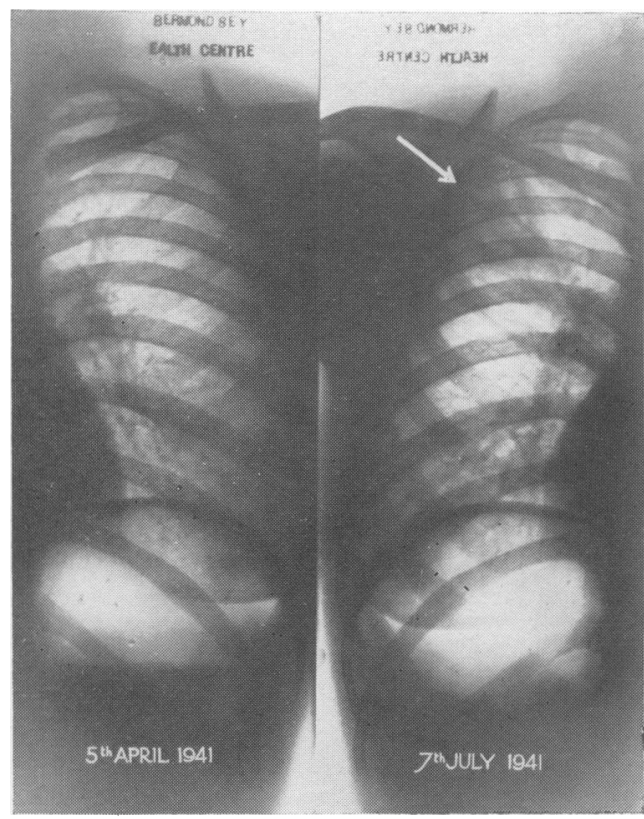

CASE I.-Two views of left lung showing formation of large cavity within three months.

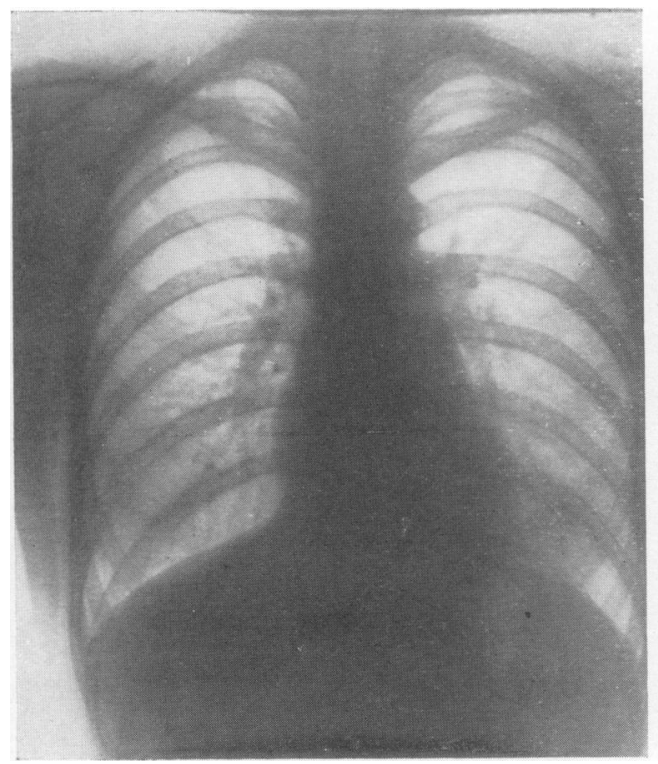

CASE III

8. XII. 42

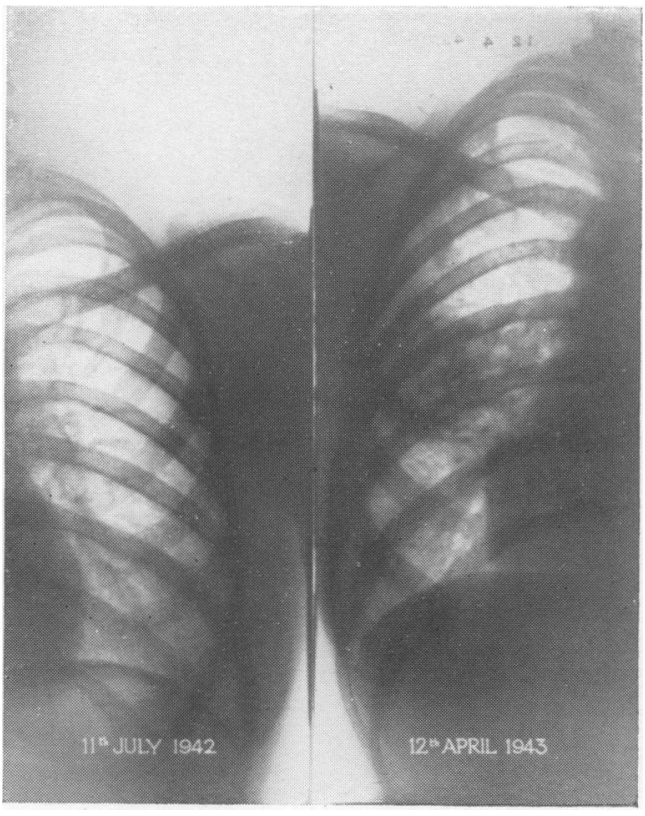

CASE II.-Two views of left lung showing extensive midzone lesion within ten months.

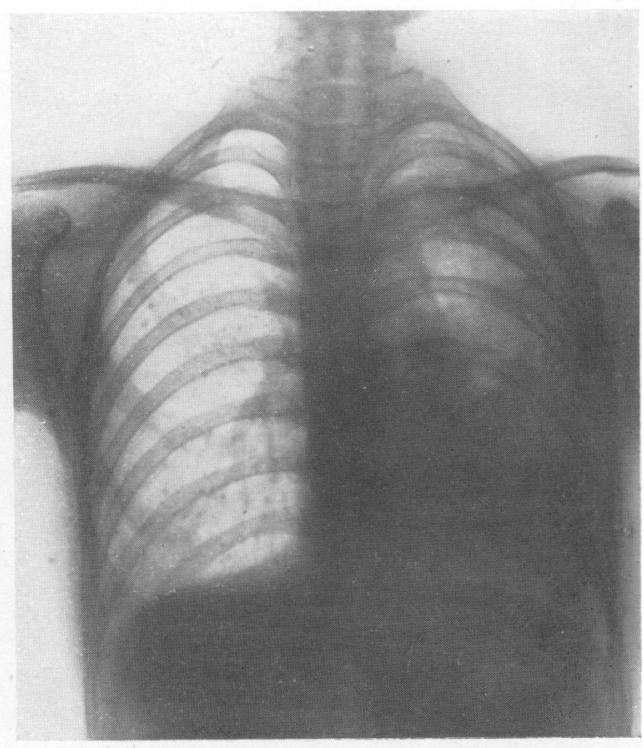

CASE III

I3. III. 43 

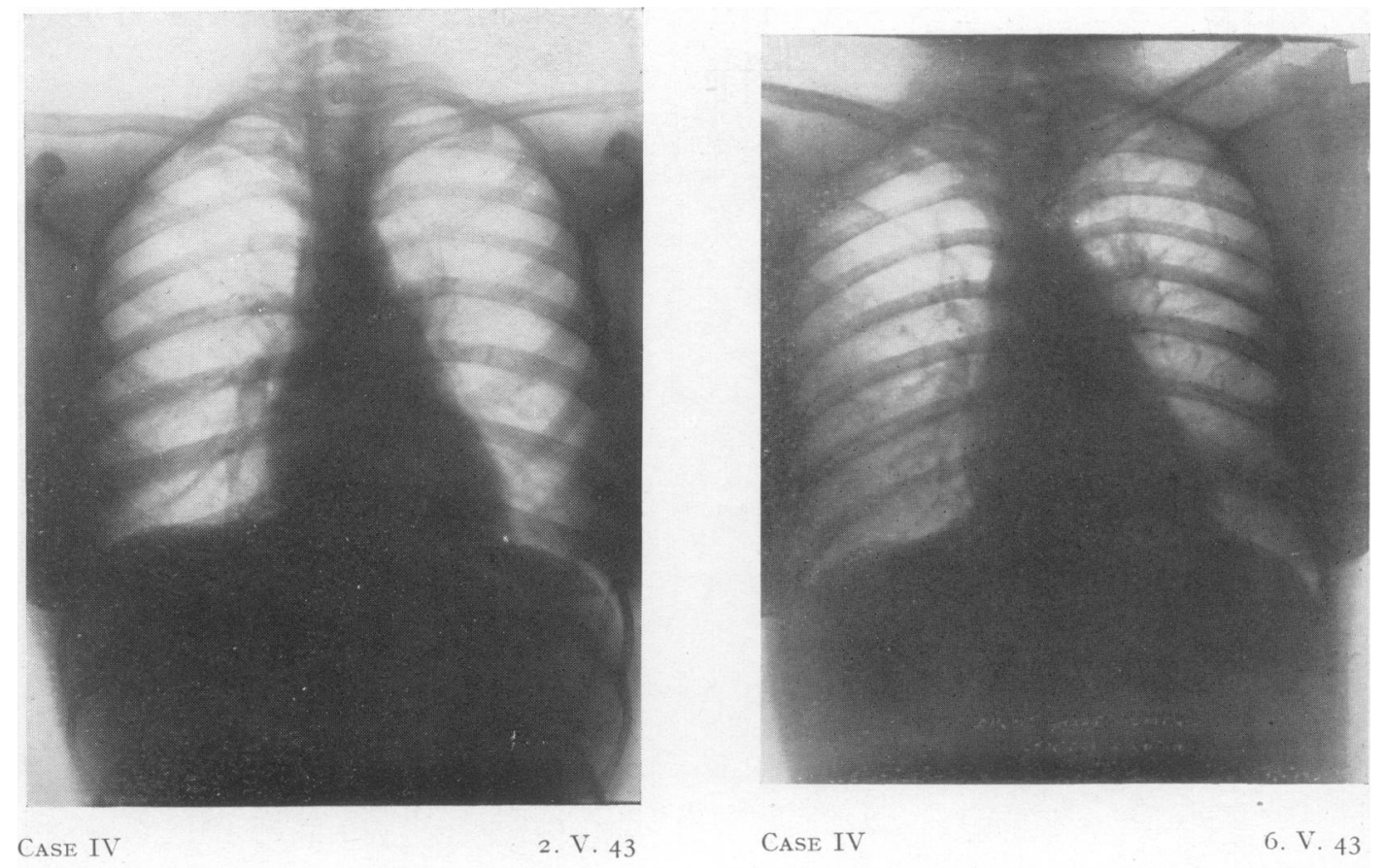

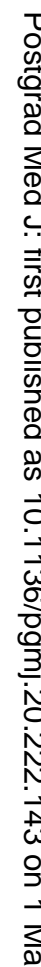
율 흘

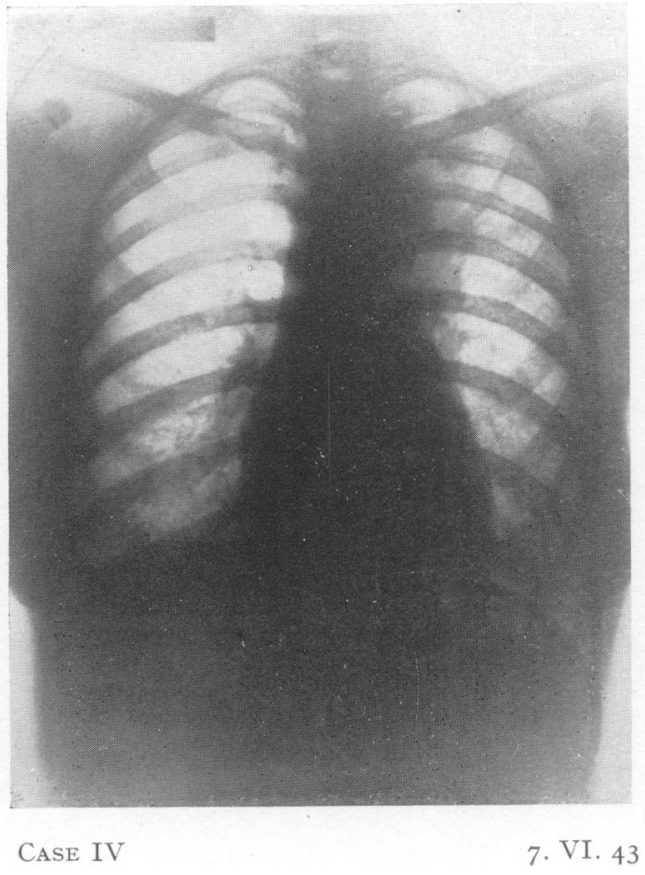


firmed this theory, and, as far back as I92I, Rist and Amenille reached the following conclusions as to the acute stage of pulmonary tuberculosis:-

"The first stage of pulmonary tuberculosis in the adult is always made up of a pneumonic attack, the lesion being generally rather extended from the beginning and showing a very early tendency to excavation. It may occupy the whole of a lung lobe a few days, and even a few hours, after the onset. We do not pretend to say that there may not be also pneumonic lesions

England and Wales. Tuberculosis Mortality. Males.

Death Rates per Million at Different Age Periods for Certain Decennia.

(The death rates for adolescents and later ages are those of Respiratory Tuberculosis.)

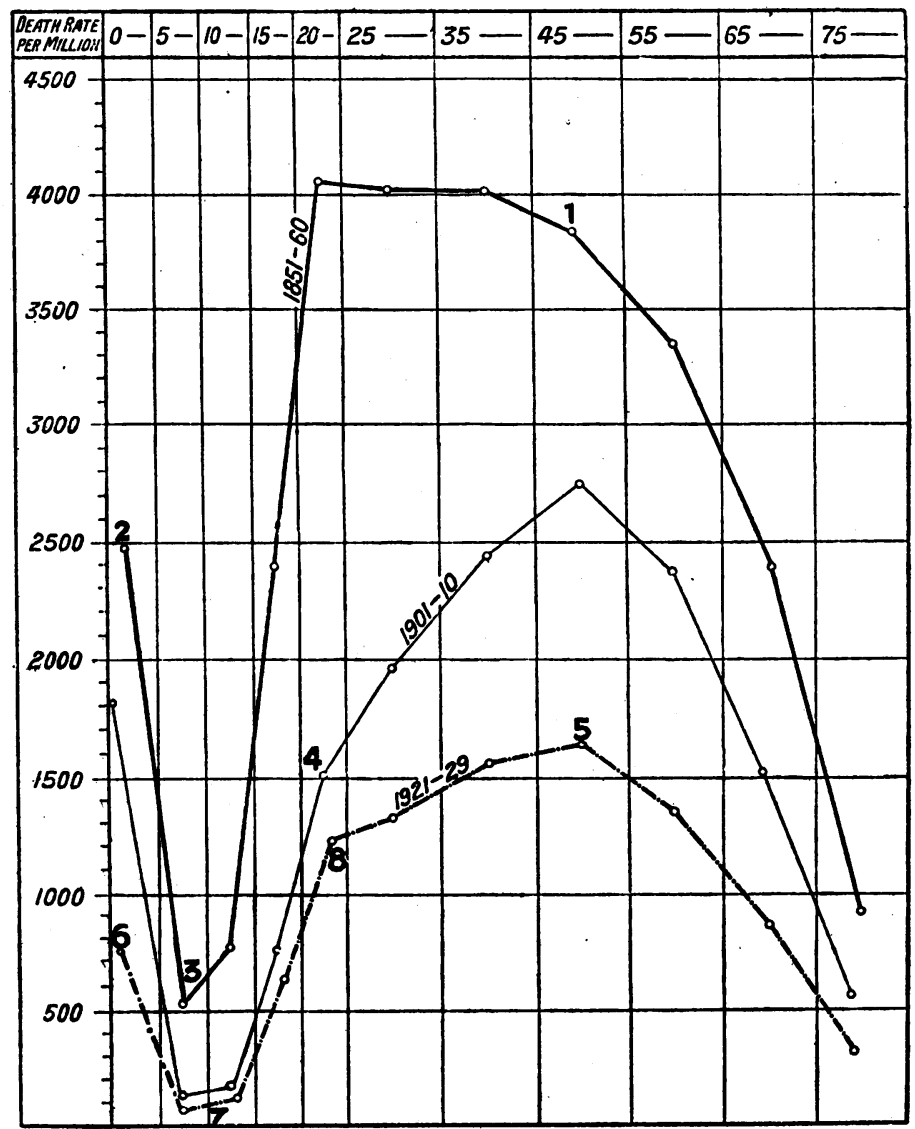

Chart 2

Suggested factors operating from I850 to I910:-

I. High middle age mortality led to high infantile mortality.

2. High infantile mortality led to 3 , a high proportion of immunes and a lower proportion of susceptibles.

3. This factor led to 4 , a decrease in adolescent mortality.

4. The marked decrease in adolescent mortality was the conspicuous phenomenon between the years 1850 to 1920 .

Conversely-Suggested factors tending to operate since r910:-

5. Decrease in middle-age mortality led to a decrease in infantile infection and mortality.

6. Decrease in infantile infection led to a decrease in the proportion of immunes and an increase in the proportion of susceptibles (Mantoux Neg.).

7. This factor led to a retardation, or even cessation, of the decline in adolescent mortality.

8. This retardation of the decline in adolescent mortality has been the conspicuous feature in the epidemiology of tuberculosis in recent years. 
which involve only a small area of lung tissue, but it seems as if such small lesions are hardly able to determine clinical symptoms, and will rapidly become quiescent and abortive. . . . The initial pneumonic lesion may eventually be totally absorbed, in some rather exceptional instances. Generally, it is only partly absorbed, leaving behind it lesions which undergo the ordinary evolution of tuberculosis. The initial lesion may become entirely caseous in some cases which then represent true caseous pneumonia. It is seldom that we find this caseous stage at the postmortem in adults, because it seems to be shortlived. Indeed, X-ray study of the initial stage of tuberculosis in adults shows how rapidly the tuberculous lesions are excavated; it takes a few days, even a few hours, so that there is hardly any space left for an intermediate stage of excavation. This is probably the reason why sputum appears so early, and why bacilli can be found in it almost from the beginning. Generally speaking, a limited area of the pneumonic patch only becomes excavated, but it may happen also that the whole of it is converted into a cavity."

Later Rist (9) (I929) expounded such an excellent description of the onset and course of pulmonary tuberculosis that we cannot do better than quote many of his passages in full:-

"The sudden onset may affect a variety of clinical features which may be conveniently classed under the following heads:

I. In a large number of cases, it has the appearance of an acute pulmonary or pleuropulmonary episode. Chills and fever initiate it, the fever being generally high, occasionally very high. Pain in the sides, coughing, expectoration are always present; the sputum may be rusty as in ordinary lobar pneumonia. Physical signs are the same as in lobar pneumonia; dullness or flatness, tubular breathing, and crepital râles. But it is a kind of pneumonia which either aborts after two, three or four days, or, on the contrary, drags on much longer than the classical nine days, becoming meanwhile more or less atypical.

The clinical picture may also, from the beginning, differ more or less from true lobar pneumonia, and is then identical with those ill-defined syndromes which go under the names of pulmonary congestion, grippe, spurious broncho-pneumonia, dry pleurisy, and so on.

2. In a lesser proportion of cases, the onset is marked by symptoms closely similar to those of an acute catarrh of the upper passages, and goes under the name of an ordinary febrile cold or of an attack of 'flu'; coryza, sore throat, rhino-pharyngitis, catarrhal laryngitis, tracheo bronchitis. When the cold is over there remains a persistent morning cough with a very moderate amount of sputum, and the patient goes on feeling a little out of sorts, running a slight evening temperature and losing weight.

3. In a very small proportion of cases the symptoms point in no way at first to a respiratory disease. The sudden onset of fever is accompanied by digestive trouble; pain in the stomach and intestine, nausea, vomiting, diarrhoea. One thinks of typhoid and food poisoning. After some days only, coughing sets in and draws attention to the chest.

4. And, finally, we have a group of our sudden cases in which chills and fever, loss of strength, muscular pains, and malaise are at first accompanied by no symptoms pointing to any localisation at all. There is neither coughing nor gastro-intestinal disturbance. The fever subsides generally before any precise diagnosis can be made, and the whole occurrence is attributed to influenza. But if a complete examination is made at that stage it will often lead to the discovery of extended and already excavated lesions in one lung.

Such are the usual clinical features which characterise the sudden onset of lung tuberculosis in the adult. On examination sometimes the signs are quite evident, but signs may be more doubtful, and sometimes there is nothing abnormal to be heard. It all depends on the localization of the lesion. If deeply seated or adjoining the shoulder joint it is bound to escape the nost expert stethacoustic examination, whereas an X-ray examination will infallibly discover an extended and often already excavated lesion, and if there is any sputum bacilli will be discovered in it.

The first stage with its sudden onset may be followed almost immediately by the classical symptoms of manifest phthisis. But it is generally not so. In most instances what takes place after the acute onset is a phase of quiescence or semiquiescence, which has the rather unfortunate effect of appeasing the, anxieties of both the patient and his physician. Fever has subsided, appetite comes back. One speaks of convalescence and even of recovery. The acute episode is checked under one of the uncompromising and misleading heads which are the cause of so many mistakes in diagnosis. There has been no thought of tuberculosis, yet some very slight symptoms persist, the most persistent of them being a little morning cough followed by 
a very reduced amount of expectoration. Although strength has more or less been restored and work has been resumed, they are easily tired and lack energy. 'Since I have had this attack of "flu," or whatever it may have been called, I have never felt quite the same man as before.' This one commonly hears. During this phase the pneumonic lesion has entered a period of shrinking and fibrosis. The solitary cavity or the more or less numerous small cavities which have been formed through the necrotic process of the initial pneumonic phase have emptied their contents and now produce only scanty secretion. This can remain so during several weeks or several months. It can even lead to ultimate healing, the cavity becoming smaller through shrinkage and undergoing a process of repair. But as a rule this quiescent phase is sooner or later followed by a renewal of illness, be it that more manifest symptoms and signs of consumption progressively develop, or be it that a new acute episode more or less similar to the first one intervenes."

In I924, German workers, such as Assman, Lydtin and Redecker, followed by describing the radiological appearances of the early or initial infiltration-a deep-seated (rarely apical) lesion which frequently led to a rapid involvement of part or whole of a lobe, or even the whole lung, by a broncho-pneumonic spread, with accompanying caseation and cavity formation. This conception, similar to that annunciated by the French writers, was accepted by a few English physicians-notably by Morlock (7) - but has not yet gained its true place in medical textbooks, and is still unknown to the real bulk of students and practitioners.

We came to realise, then, that adolescent pulmonary tuberculosis (in particular) occurs mainly in previously healthy persons (often with a contact history). The onset of the disease is comparatively sudden, and is often accompanied by a short acute febrile attack with indefinite symptoms. This pyrexial attack may pass off in a few days; the patient feels himself again, and returns to work, but the cough continues.

"It will be seen"-writes Morlock-“that these clinical manifestations, particularly in those cases without physical signs in the chest, are extremely likely to be regarded wrongly as 'influenza,' and it is a fact that many are at first diagnosed as such; the febrile period having ended, the patient is allowed to return to work, the cough persists, and constitutional signs make their appearance. By the time the disease is diagnosed, the initial infiltration has broken down to form a cavity, with or without an accompanying aspiration spread. The constitutional changes-loss of weight, lassitude, anorexia, night sweats - which have long been regarded as the earliest manifestations of this disease, are, in reality, quite late symptoms."

Is this not the true cause of our many failures rather than the all too prevalent idea that patients will not consult their doctors till the disease is advanced? In this connection also we must understand that a widespread lesion-as shown by X-ray-is not necessarily a late lesion when measured by time (even in weeks). Those of us with extensive and ready facilities for repeated radiological investigation are coming to realise also that these soft rapidly spreading lesions will arise comparatively suddenly in a person who, some time previously, presented a perfectly normal X-ray. In other words, these soft proliferative lesions, which, in our opinion, do account for the bulk of pulmonary deaths (either unnotified or within a few months of notification), are not preceded by the small hard lesions now so frequently described as the lesions of asymptomatic pulmonary tuberculosis.

Wingfield (13) also has mentioned the sudden occurrence of tuberculous lesions in the lung. They can arise in the seemingly healthy. How shall this conception, he asks, affect our routine treatment? "It calls first for a more intensive use of X-rays in all types of mild disease in an endeavour to catch the secondary or the early intermediate lesion before it has spread too far -for both are then readily curable."

Believing that the onset of pulmonary tuberculosis is frequently an acute one, but with relatively mild symptoms, we came to the conclusion, as did continental physicians, that in general practice the incipient stage of the disease is often missed. The acute onset is too often treated as bronchial catarrh, influenza, pleurodynia, or one of many innocuous ailments. The true nature of the patient's illness may not be suspected until the first or second exacerbation, following upon a period of relative quiescence. By this time the disease may have extended considerably, prognosis has definitely worsened, and the period of treatment required to restore the patient even to a reasonable state of semi-chronicity, has been greatly increased.

The essential requirement for a prompt diagnosis may be stated very briefly-an X-ray of the chest immediately after the onset of symptoms-but as a practical measure it is not so easy to procure. We had considered this problem for some years past, and prior to the War 
we were in contact with the London Panel Committee with a view to encouraging the wider use of immediate $\mathrm{X}$-ray examination of cases presenting suspicious symptoms. These contacts were broken by the onset of the war, and it seemed as though we must abandon hopes of improving the position. In I942, however, we secured the support of our respective Medical Officers of Health, and of Dr. F. L. Telfer, radiologist to the Bermondsey Council. In December of that year we approached, as an experiment, a limited group of practitioners in each borough, and they agreed to refer for an immediate $\mathrm{X}$-ray any patient complaining of the following minor symptoms which might be due to disease within the chest:-

ChART 3

SUGGESTED PROVISIONAL DIAGNOSIS

$\left.\begin{array}{l}\text { Cough } \\ \text { Bronchitis } \\ \text { Dyspnoea } \\ \text { Laryngitis }\end{array}\right\} \begin{aligned} & \text { including } \\ & \text { seniles. }\end{aligned}$

Bronchial Catarrh

Haemoptysis (including seniles)

Ischio-rectal Abscess.

\section{Influenza.}

Febrile Chill.

P.U.O.

Pleurisy, pleurodynia or pain in chest.

\begin{tabular}{|c|c|}
\hline oss of weight & \\
\hline $\begin{array}{c}\text { Anaemia and } \\
\text { Debility }\end{array}$ & $\begin{array}{l}\text { particularly } \\
\text { females }\end{array}$ \\
\hline $\begin{array}{l}\text { Amenorrhoea } \\
\text { (unexplained) }\end{array}$ & aged $I_{5-30}$ \\
\hline
\end{tabular}

The patients were to attend the X-ray Department without prior clinical examination, and no mention would be made of tuberculosis. Close contact was established with the individual practitioners by letter and personal interview, and the experiment met with immediate success. By June 30, I943, I,III cases had been thus examined in the two boroughs with the remarkable discovery of 2.8 per cent active tuberculosis. What was more encouraging was the number of early cases found, in the proportion of two uni-lateral to one bi-lateral, many of the unilateral cases having small lesions with a good prognosis. Subsequently the facilities were extended to every practitioner in the two boroughs. Up to December 3I, I943, 2,473 cases had been examined under this scheme, active tuberculous lesions forming 3.23 per cent of the total, the proportion of uni-lateral to bi-lateral cases being not quite two to one. Practitioners. as a whole have accepted the idea with enthusiasm, and we have no doubt that with their mounts ing co-operation it should be possible to increase still further the proportion of cases in a really early stage of the disease. One has but to see and evaluate a few of these early cases to realise the vital importance of attaining an early diagnosis and to understand the contribution such an experiment has already made in the alleviation of our old-standing problem.

We wish to mention also the much greater use which should be made by practitioners of bacteriological examination of the sputum in the early stages of lung disease. As was mentioned earlier, in the active spreading lesions, tubercle bacilli will often be found at the onset.

The necessity for early X-ray examination in the case of bony injuries is now recognised on all sides, and has its legal bearing in any action which might be brought for possible negligence. The day has come when such a possibility must be borne in mind also with regard to the adequate diagnosis of pulmonary disease.

Mass radiological investigations of factory workers are now being conducted throughout the country, and it behoves members of the profession to beware lest tuberculosis may thus be discovered in a case who, unwittingly, has been treated for months as a simple bronchitis. A decision has already been reached in the courts providing substantial damages against a practitioner on account of such a mistaken diagnosis.

A full analysis of the results in the above-mentioned scheme of examination is set out in the table on page $\mathbf{r}_{50}$.

Finally, we may consider possible future developments. We have evolved a scheme for the early radiological examination of an abnormal symptomatic population group. Apart from its probable success in the field of tuberculosis, whither will it lead us?

May it not succeed in opening up a real branch of preventive medicine? We are here given an opportunity for the study of early lesions of differing types. Surely we may seize the chance with a view to the ultimate prevention of much misery and incapacitation in later years. How much do we yet know of the early management and control of incipient disease-from the preventive aspect? The apparently inevitable advance-in the individual-of asthma, chronic bronchitis, emphysema, hypertension, can each yield evidence of our present failures !

A high percentage of cardiac abnormalities will be revealed. Will the Tuberculosis Dis- 
pensary not evolve into the true chest clinic embracing the study and supervision of diseases both of the heart and lungs?

We can therefore see before us a ripe opportunity for research in which the general practitioner, the tuberculosis officer, and the radiologist may well play leading parts, and in so far as they succeed they can influence the education of the future practitioner in the direction of preventive rather than curative medicine.

\section{Summary}

I. The administration of tuberculosis must be based on a true clinical conception of the disease.

2. The onset of pulmonary tuberculosis is often acute with rapid spread and early excavation. This factor undoubtedly leads to a high percentage of deaths occurring within a few months of notification.

3. To achieve a good prognosis, diagnosis must be immediate. This can be attained more readily by extensive radiological examination of patients with minor symptoms.

4. Much wider use should be made of bacteriological examination of the sputum at the onset of the disease.

5. If early diagnosis is secured, it must be followed by immediate treatment.

6. Local authorities must be prepared to increase facilities for diagnosis on the above lines, and practitioners should themselves press for such facilities if not already available.

We wish to express our thanks to the Medical Officers of Health of Bermondsey and Southwark, to Dr. F. L. Telfer, Radiologist to the Borough of Bermondsey and to the practioners of the two Boroughs for their co-operation in this experiment.

\section{BERMONDSEY AND SOUTHWARK.}

Mass Radiological Investigation of "Minor" Chest Symptoms for Practitioners.

Results from 7th December, 1942, to 31st December, 1943.

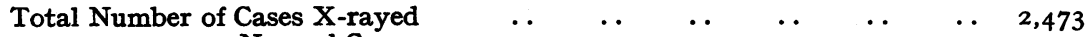

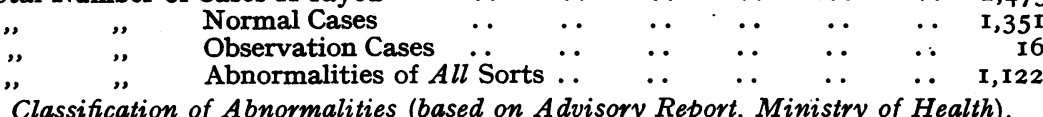

1. Abnormalities of bony thorax

2. Chronic bronchitis and emphysema

3. Preumonia (non-tuberculous)

4. Broncho-pneumonia (non-tuberculous)

4b. Pneumonitis (atypical pneumonia)

5. Consolidation (of unknown cause) ..

6. Bronchiectasis

7. Pulmonary fibrosis (non-tuberculous)

8. Pneumokoniosis

10. Basal fibrosis (e.g. oblit. costophrenic sinus)

II. Pleural thickening

12. Pleural and interlobar effusion (non-tuberculous)

14. Intrathoracic new growth

16. Cardio-vascular lesions (acquired) .

17. Miscellaneous

20. Tuberculosis-active primary lesions, including epi-tuberculosis

21. Tuberculosis (inactive primary lesions, calcified nodes)

22. Tuberculosis (adult type-active-unilateral)

23. Tuberculosis (adult type-active-bilateral)

24. Tuberculosis (adult type-inactive)

25. Tuberculosis-Pleural effusion

Total in Groups 20, 22, 23, $25=80$ (Active Tuberculosis).

No. of Cases.

$\begin{array}{lllllllll}\cdots & \ldots & \ldots & \ldots & \ldots & \ldots & \ldots & \ldots & 49\end{array}$

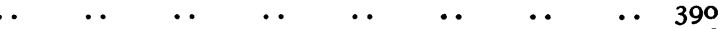

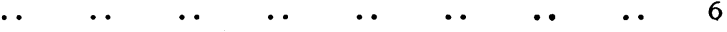

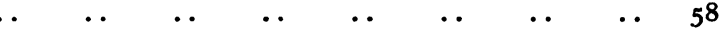

$\begin{array}{lllllllll}\text {. } & \ldots & \ldots & \ldots & \ldots & \ldots & \ldots & \ldots & \text { I }\end{array}$

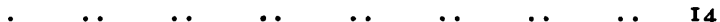

$\begin{array}{lllllllll}\text {. } & \ldots & \ldots & \ldots & \ldots & \ldots & \ldots & \ldots & 33\end{array}$

Percentage of Active Tuberculosis found $=3.23$ per cent.

\section{REFERENCES}

I. BROWNLEE, J., "An Investigation into the Epidemiology of Phthisis in Great Britain and Ireland," Med. Res. Com. Spec. Rep. Ser. Nos. 18, 46.

COUTTS, F. J. H., Nat. Assoc. Prev. Tuberc. Trans. 18th Annual Conf., 1932.

. COX, G. LISSANT, "Fate of Young Children in Tuberculous Households," Tubercle, 1929, 10, 497.

DOW, D. J., and LLOYD W. E. Brompton Hosp. Res. Dept. I930, No I, Tub. Mortality in Children.

HART, P. D'A., and WRIGHT, G. P., Tuberculosis and Social Conditions in England, 1939, N.A.P.T., Lond.

HILL, BRADFORD. J. Roy. Stat. Soc., 1936, 99, 2.

. MORLOCK, H. V., Brit. Med. J., $1931,1,702$.

RIST, E. and AMËNILLE, P., Bull. et Mém. de la Soc. Méd. d. Hóp. de Paris, 1921, 12, 2.

RIST, E., and AMENILLE, P., Paris Médicale, 1922, 7, I.

RIST, E., Canadian Med. Assocn. J., I929, 21, 143.

10. TATTERSALL, N., A nn. Rep. City of Leeds, M.O.H., Tuberc. Sec., 192.

II. THOMPSON, B. C., Tubercle, I942, 23, I39.

13. WINGFIELD, R. C., Brit. Med. J., I933, I, 179. 